\title{
UMA ABORDAGEM DO POEMA EM MATERIAL DIDÁTICO: O LEITOR EM FOCO
}

\section{A POEMA APPROACH TO TEACHING MATERIAL: THE FOCUS READER}

\section{Cristina Rothier Duarte ${ }^{1}$ Girlene Marques Formiga ${ }^{2}$}

Resumo: Apresentamos como proposta de estudo para este trabalho a análise do material didático do curso de Letras, modalidade EaD, do Instituto Federal da Paraíba - IFPB, no que diz respeito ao ensino do gênero poema para o Ensino Fundamental II. Metodologicamente, empregamos a pesquisa bibliográfica de cunho qualitativo-interpretativo para a realização do exame do material aludido utilizado como referência básica na formação docente inicial do referido Instituto. Como base teórica deste estudo, utilizamos, entre outros, Rouxel (2012, 2013a, 2013b), Aguiar e Bordini (1993) e Cosson (2014a, 2014b).

Palavras-chave: material didático; formação inicial; leitura literária.

Abstract: We present as a study proposal for this work the analysis of the didactic material of the course of Letters, modality EaD, of the Instituto Federal da Paraíba - IFPB,with respect to the teaching of the genre poem for Elementary School II. Methodologically, we used the qualitative-interpretative bibliographical research to carry out the examination of said material used as a basic reference in the initial teacher training of said Institute. As a theoretical basis of this study, we use, among others, Rouxel (2012, 2013a, 2013b), Aguiar and Bordini (1993) and Cosson (2014a, 2014b).

Keywords: didactic material; initial formation; literary reading.

\section{Introdução}

A leitura literária na escola é tema de discussões diversas por parte de estudiosos que, não raro, questionam as práticas escolares circuladas nesse universo. As contendas parecem se avolumar quando se refere ao modo de abordar o poema, gênero que não ocupa um espaço privilegiado na formação do leitor. A poesia vista como "uma frágil vítima da escola" (LAJOLO, 2008) ecoa no cenário escolar à medida que se registra tratamento restrito por

\footnotetext{
${ }^{1}$ Mestre em Letras pela UFPB e doutoranda em Literatura pela UFPB. E-mail:cristinarothier@hotmail.com

2 Doutora em Letras pela UFPB. Professora do IFT da Paraíba. Divide a liderança do Grupo Tecnologias colaborativas no ensino e redes aprendentes na educação profissional na linha Práticas educativas na Educação Profissional e Tecnológica. Integra ainda o grupo de pesquisa Estágio, Ensino e Formação Docente (UFPB), atuando na linha Leitura, Literatura infantil, juvenil e ensino. E-mail: girlene.formiga@ifpb.edu.br
} 
certos manuais didáticos que pouco valoriza os arranjos linguísticos, capazes de tocarem a sensibilidade do leitor. Salvaguardadas as abordagens por parte de mediadores responsáveis por favorecer o encantamento pelo gênero, o despertar de emoções, o desenvolvimento da imaginação e da sensibilidade do leitor são obscurecidos em favor do trabalho com atividades, por exemplo, que exploram o ensino de língua e a produção textual.

Na contramão dessa ideia, a formação inicial, via curso de Licenciatura em Letras do Instituto Federal da Paraíba que integra à Rede Federal, conhecida pela sua trajetória histórica na educação profissional, científica e tecnológica nas diferentes modalidades de ensino, visa a fazer jus a uma concepção política de que a leitura pode promover a autonomia do cidadão. Aludida como "elite da escola pública de ensino médio, referência em educação técnica" (SALDAÑA, 2018, online) ${ }^{3}$ a Rede Federal permanece no ranking dos resultados no desempenho dos alunos de ensino médio no Enem 2018, ${ }^{4}$ apontando os institutos federais no topo das escolas públicas (INEP/MEC 2019). Acrescente ao fato o resultado do Programa Internacional de Avaliação de Estudantes (PISA), realizado pela Organização para a Cooperação e Desenvolvimento Econômico (OCDE), em 2015, que indica igualmente um bom desempenho da Rede na área de Leitura. O contexto apresentado nos instiga a investir na formação inicial de professores de Letras, e, por conseguinte, no foco na formação leitora, incluindo a literária, com vistas a contribuir para a construção do indivíduo social, cultural e para o desenvolvimento do pensamento crítico.

Propícia quanto ao acesso no ambiente educacional, a literatura deve extrapolar a sua utilização como uma ferramenta utilitária pedagógica de ensino e protagonizar o lugar que lhe cabe em busca da formação do seu leitor. Nessa perspectiva, é pertinente a reflexão sobre a importância dos primeiros contatos com a leitura, de maneira a provocar os docentes a adotarem, como prática profissional, práticas sistematizadas que concorram para a formação do leitor literário.

No contexto em que a literatura infantil e juvenil se apresente como fundamental para o letramento literário do indivíduo, neste artigo, pretendemos analisar o conteúdo do material básico relativo ao componente curricular Metodologia do Ensino de Literatura ofertado aos

\footnotetext{
${ }^{3}$ Folha de São Paulo, 14 jan. 2018.

${ }^{4}$ Folha de São Paulo, 18 jun. 2019.
} 
graduandos do curso de Letras a distância do IFPB, tendo em vista a adequação à formação inicial desses discentes delimitada ao ensino da poesia no Ensino Fundamental.

As concepções aqui representadas se fundamentam Rouxel, (2012, 2013a, 2013b, 2013c), Bordini e Aguiar (1988) na ideia de contribuir para a aproximação entre leitor e texto literário.

As pesquisas atuais em didática da literatura, fundadas no estudo muito preciso de transcrições de curso, mostram que é a atenção dada ao aluno, enquanto sujeito, a sua fala e a seu pensamento construído na e pela escrita que favorece seu investimento na leitura (ROUXEL, 2013c, p. 31).

Adentrar a esse campo de investigação favorece analisar se o curso a forma proposta curricular é capaz de oferecer caminhos para que, uma vez em sala de aula, o professor formado em Letras pelo IFPB - por extensão a outras instituições - assuma de forma eficaz seu papel de mediador para formação de leitores de obras literárias, especialmente de poemas. Nesse sentido, este trabalho - cuja preocupação é o fazer docente -, poderá, via transversa, trazer contribuições para a comunidade escolar sobre o ensino de Literatura, notadamente da poesia.

\section{A poesia no Ensino Fundamental II: estudo do material didático voltado à formação docente}

O componente Metodologia do Ensino de Literatura, de acordo com o Projeto Pedagógico do Curso de Letras, modalidade a distância, do IFPB, compõe o eixo articulador dos conhecimentos a serem ensinados e dos conhecimentos filosóficos educacionais e pedagógicos que fundamentam a ação educativa; apresenta a carga horária de 60 horas sendo 45 de horas teóricas e 15 práticas -, equivalente a 4 créditos. A associação entre teoria e prática da formação docente segue o estabelecido na Resolução CNE/CP n ${ }^{\circ}$ 02, de 01 de julho de 2015, que define as Diretrizes Curriculares Nacionais para a formação inicial em nível superior (cursos de licenciatura, cursos de formação pedagógica para graduados e cursos de segunda licenciatura) e para a formação continuada. Nessa perspectiva, a ementa de Metodologia do Ensino de Literatura prevê o estudo da "Análise de propostas pedagógicas para o ensino de Literatura e suas abordagens metodológicas dos conteúdos.” (IFPB, 2012, p. 78).

De acordo com o fluxograma do curso, a disciplina Metodologia do Ensino de Literatura é ministrada no $5^{\circ}$ período do curso, tendo como pré-requisito o componente 
curricular Literatura e Ensino, fixado na Matriz no $2^{\circ}$ semestre. Do início do curso até o momento em que estudam a disciplina Metodologia do Ensino da Literatura, os graduandos têm a oportunidade de cursar disciplinas que tratam de teorias e estudos literários, do universo ficcional da literatura, ou seja, têm a oportunidade de acumularem conhecimentos pertinentes ao estudo da literatura suficientes para subsidiar métodos e abordagens acerca do texto literário.

Para fins de equivalência de carga horária presencial, estabelecida pelo IFPB, o componente possui, no total, 14 aulas $^{5}$ referentes ao material básico, disponibilizadas em formato PDF na plataforma Moodle, no decorrer do semestre letivo, para os alunos matriculados na disciplina. Tais aulas apresentam como conteúdo o ensino de gêneros literários variados (poema, conto, romance, cordel etc.) no Ensino Fundamental II e no Ensino Médio. Todas as aulas apresentam uma estrutura fixa composta por seis partes: 1. "Objetivos de aprendizagem”, em que é apresentado de forma topicalizada o conteúdo a ser abordado na aula; 2. "Começando a história", momento em que o tema é introduzido; 3. "Tecendo conhecimento", quando o tema da aula é abordado sob um enfoque teórico; 4. "Aprofundando o conhecimento", em que são indicadas referências bibliográficas mediante a imagem da capa da obra e de uma resenha curta para leituras acerca do tema tratado na aula; 5. "Trocando em miúdos", trazendo uma síntese do que foi estudado; e, por fim, 6. "Autoavaliando", apresentando questionamentos para que o cursista possa realizar uma autorreflexão acerca do conhecimento construído e assimilado durante a aula.

Entre as aulas do componente curricular em estudo, tem-se adotado a autorreflexão sobre práticas de leitura dos cursistas, mediante depoimentos que registram em fóruns destinados a esse fim. Tais registros têm como propósito conscientizar o licenciando acerca do hábito de leitura, característica que deve ser cultivada por propiciar uma maior facilidade para o professor na formação de leitores.

Os dados tratados nesta seção do artigo estão situados, mais especificamente, na aula 01 - "Métodos do ensino da literatura", e na aula 02 - "Poesia no ensino fundamental", do material didático do curso. A escolha de tais conteúdos para o estudo em tela se justifica por

\footnotetext{
${ }^{5} \mathrm{As}$ aulas 1 a 14 do componente ora tratado foram elaboradas pelos doutores: Daniela Maria Segabinazi, professora da UFPB, Andrea Maria de Araújo Lacerda, professora do IFRN; e José Helder Pinheiro Alves, professor da UFCG. Convém ainda esclarecer que as aulas que compõem o material básico do curso de Letras são produzidas por professores do próprio IFPB ou por especialistas de outras instituições de ensino.
} 
tratar de aspectos gerais do ensino de literatura e por abordar o poema, gênero considerado problemático para se trabalhar no Ensino Básico.

Partindo para a descrição da aula 1 - "Métodos do ensino da literatura", estão previstos como objetivos apontados dessa aula:

- Apresentar metodologias de abordagem do texto literário na sala de aula do ensino fundamental e médio;

- Estudar diferentes métodos de abordagem do texto literário na sala de aula;

- Compreender a necessidade de metodologias para o ensino de Literatura na escola (IFPB, 2014, p. 11).

No tópico seguinte, "Começando a história", a aula explicita que a disciplina oferece a "oportunidade de conhecer várias metodologias para abordar o texto literário na escola", esclarecendo para o cursista que tais metodologias apresentadas se tratam de "sugestões que poderão ser adaptadas a partir da sua própria vivência e da de seus alunos.” (IFPB, 201-, p. 12).

A aula, ainda nesse tópico, acentua que tais metodologias visam à formação do leitor, de modo que abordam o texto literário de maneiras distintas do enfoque historiográfico ou utilitarista; ressalta ainda o lugar do leitor e o seu contexto como ponto de partida para as metodologias adotadas pelo professor; bem como a importância de um planejamento das aulas de literatura, de forma que as metodologias vêm a serviço do professor para colaborar no êxito do objetivo desejado. A fim de fundamentar essa necessidade, o texto nos traz uma citação de Aguiar e Bordini (1988) ${ }^{6}$, ratificando o que foi exposto.

No tópico que segue, "Tecendo conhecimento", antes da exposição sobre as metodologias para o ensino da literatura que serão tratadas na aula, há uma observação:

Em geral, as sugestões metodológicas apresentadas primam por uma abordagem que coloque o leitor como sujeito de sua leitura. Isso significa que não se busca, por meio dos métodos, ensinar um saber sobre Literatura, antes, favorecer uma vivência mais profunda com os textos literários de diferentes gêneros e épocas. (IFPB, 2014, p. 14).

Como podemos notar, o material didático assume uma concepção de ensino da literatura enquanto ferramenta para promoção da aproximação entre o texto e o eleitor, endossando uma série de ações docentes nas aulas de literatura que colaboram para a formação do leitor. Desse modo, percebemos que o material didático do IFPB prioriza a leitura literária frente a qualquer outro objetivo que possa parecer relevante para o ensino de

\footnotetext{
${ }^{6}$ Trata-se da edição utilizada nas fundamentações das aulas do curso de Letras do IFPB. Para os nossos estudos e citações, consultamos a $2^{\text {a }}$ edição, ano 1993.
} 
literatura, configurando-se, assim, consonante Rouxel (2013a), entre outros estudiosos, que o vínculo afetivo com a leitura do texto literário se dá mediante o emprego de metodologias valorizadoras da experiência de leitura do aluno. Pois, de acordo com a autora, a escola, local que deveria ser o adequado para as práticas leitoras, via o didatismo com que vem tratando a literatura, só tem promovido o afastamento do aluno leitor.

De fato, se os estudos sociológicos estiverem corretos (BAUDELOT; CARTIER; DETREZ, 1999), a falta de interesse dos jovens pela leitura emerge na escola, no momento em que essa atividade torna-se um exercício escolar avaliado, tendo por objeto obras complexas [...]. (ROUXEL, 2012, p. 14).

Adiante, a aula passa a tratar do método recepcional e do método criativo trabalhados por Aguiar e Bordini (1988); e das sequências didáticas e dos círculos de leitura de Cosson (2006; 2014a; 2014b). As teorias selecionadas para a formação inicial docente no tocante ao ensino da literatura, embora clássicas, são atualizadas e têm o escopo de assegurar o lugar da leitura literária no ambiente escolar, mediante a abordagem contextualizada do texto literário com as diversas experiências do aluno e a leitura integral da obra - elementos primordiais para despertar o gosto dos jovens pela literatura e, consequentemente, para promover o seu letramento literário.

É interessante notar que o tratamento que a aula confere à teoria trazida à baila não tem o intuito de torná-la intocável. A respeito do método recepcional, a aula flexiona seus objetivos e suas etapas, esclarecendo que "nem todos os objetivos são possíveis de serem aferidos, bem nem todas as etapas se efetivam na ordem apresentada.” (IFPB, 2014, p. 11), o que faz com que o cursista perceba que a impossibilidade de efetivação de algum dos objetivos ou etapas não é capaz de frustrar o método. Note que serão as circunstâncias reais que ditarão as "regras do jogo", mas adverte: "[q]uantos às etapas, é importante procurar segui-las, mas também não como uma camisa de força.” (IFPB, 2014, p. 11).

Outro método de ensino da literatura abordado na aula 1 é o criativo, também de Aguiar e Bordini (1988). A sua apresentação é realizada sucintamente, trazendo suas ideias principais como o conceito, os objetivos e as etapas, e, de igual modo, como fez quanto às etapas do método recepcional, permite o ajustamento de acordo com a realidade da sala de aula:

Como veremos na elaboração das aulas, a situação da sala de aula é que determina as etapas. Algumas podem ser juntas, outras em ordem diferenciada. Por exemplo, quando o professor não conhecer bem a turma, poderia começar com a etapa 2 
[coleta desordenada de dados] - que não necessita ser desordenada. (IFPB, 2014, p. 17).

Como vemos, apesar de Aguiar e Bordini advertirem que a sequência das etapas não deve ser alterada ou suprimida (1993, p. 153), a flexibilização da aula do componente em estudo condiz com a realidade. Tonar uma metodologia rigorosa, faz-nos pensar em uma idealização tanto do método, quanto das circunstâncias, o que, na maioria das vezes, não corresponde à prática. Um mesmo plano de aula, por exemplo, nem sempre funciona e alcança os mesmos resultados em turmas distintas. Os recursos e o ambiente escolar podem não ser favoráveis à execução de etapas mais dispendiosas. No entanto, não deve o professor suprimir totalmente uma metodologia que, se adaptada de acordo com a realidade, pode ser exitosa para o ensino de literatura.

Dando continuidade às metodologias elencadas na aula em apreço, o material passa a tratar das sequências didáticas de Cosson. A primeira a ser abordada é a chamada sequência básica. Mantendo coerência com a forma como vinha versando as metodologias anteriores, a aula faz uma síntese teórica, ocupando-se das etapas (motivação; introdução da obra e do autor; leitura; interpretação - fase interna e externa).

A segunda sequência aludida é a sequência expandida, em que o material não se dedica a pormenores, chamando apenas atenção para os seguintes fatos: os momentos previstos da sequência básica, nessa metodologia, são mais aprofundados; e a contextualização da obra e do autor pode seguir caminhos variados segundo a abordagem escolhida pelo professor: teórica, histórica, estilística, poética, crítica, presentificadora e temática.

As metodologias, portanto, são apresentadas na aula resumidamente requerendo do cursista uma leitura mais aperfeiçoada do referencial teórico, como se dá em aulas presenciais. No entanto, já oferecem ao licenciando informações gerais e servem de orientação para um estudo teórico, facilitando a compreensão da fonte original no momento de sua leitura.

Outro ponto da aula que devemos ressaltar são as considerações apresentadas no que se refere ao planejamento das contextualizações e à escolha da sequência. $\mathrm{O}$ material alerta para a necessidade de: (a) a contextualização ser determinada a partir da eleição da obra e de acordo com o interesse da turma; (b) "a avaliação do texto literário não [...] ser castradora, punitiva, pelo contrário, [...] que lev[e] em consideração as impressões dos alunos” (IFPB, 
2014, p. 19); (c) as impressões equivocadas serem desconstruídas; (d) a leitura não ser imposta. Observações, portanto, importantes e coerentes ao ensino de literatura nos moldes das teorias que sobrelevam a perspectiva do leitor, como a teoria da recepção, a teoria do leitor real e a teoria do efeito.

Outra obra adotada, para orientar os cursistas quanto ao ensino da literatura, é Círculos de leitura e letramento literário (2014a), de Cosson. Sobre ela, a aula apresenta ideias pontuais, tais como o cerne da teoria - os modos de ler de acordo com a abordagem acolhida pelo leitor; e os modos de ler, a partir de cada um dos eixos (contexto, texto, intertexto).

Após a exposição sumária dos doze modos de leitura, a aula, mais uma vez, flexibiliza a teoria, considerando tais modos preceituados por Cosson como "possibilidades de adentrar no texto literário; não quer[endo] dizer que são os únicos [...]" caminhos que o professor deve seguir "para conseguir criar a rede de sentidos estabelecida pelo texto." (IFPB, 2014, p. 20).

A aula trata ainda rapidamente das estratégias de leitura que Cosson elenca a partir da proposta de Girotto e Souza (2010) - ativação do conhecimento prévio; conexão; inferência; visualização; sumarização e síntese, além de trazer observações quanto à leitura em voz alta como forma de socialização; à formação de círculos de leitura para discussão de obras literárias; e aos tipos de círculo de leitura - estruturado, semiestruturado e a aberto ou não estruturado.

Constatamos, diante do que vimos, que a aula em estudo não se limita a apresentar as bases teóricas para o ensino de literatura. Ao contrário disso, vai além, pois abre espaço para o cursista refletir sobre os referenciais trabalhados, a fim de, quando da prática escolar, conferir-lhe segurança para aplicá-los com maior liberdade, adequando-os à realidade das turmas caso haja necessidade, mediante supressão, adição ou mescla de etapas previstas nas metodologias originais.

Encerrada a exposição teórica, a aula traz o tópico "Exercitando", convidando o cursista a refletir sobre uma questão levantada na obra de Aguiar e Bordini que retrata uma problemática recorrente na vivência de alunos e de professores da Educação Básica: o preterimento do debate frente às aulas expositivas:

Coloque em confronto os dois procedimentos: debate e aula expositiva. Por que a predominância de um sobre o outro se dá nas aulas de Literatura? $\mathrm{O}$ que isto revela? Os métodos até aqui apresentados se adequam mais à aula expositiva ou ao debate? Por fim, poste a sua resposta no fórum desta aula. (IFPB, 201-, p. 22). 
No tópico seguinte, "Aprofundando o conhecimento", as recomendações de leitura atualizadas sobre o tema, de fato, ampliam a discussão proposta na aula, haja vista a indicação de duas obras relevantes sobre o ensino de literatura:

Figura 1 - Recomendação de leitura da aula 1 do componente MEL

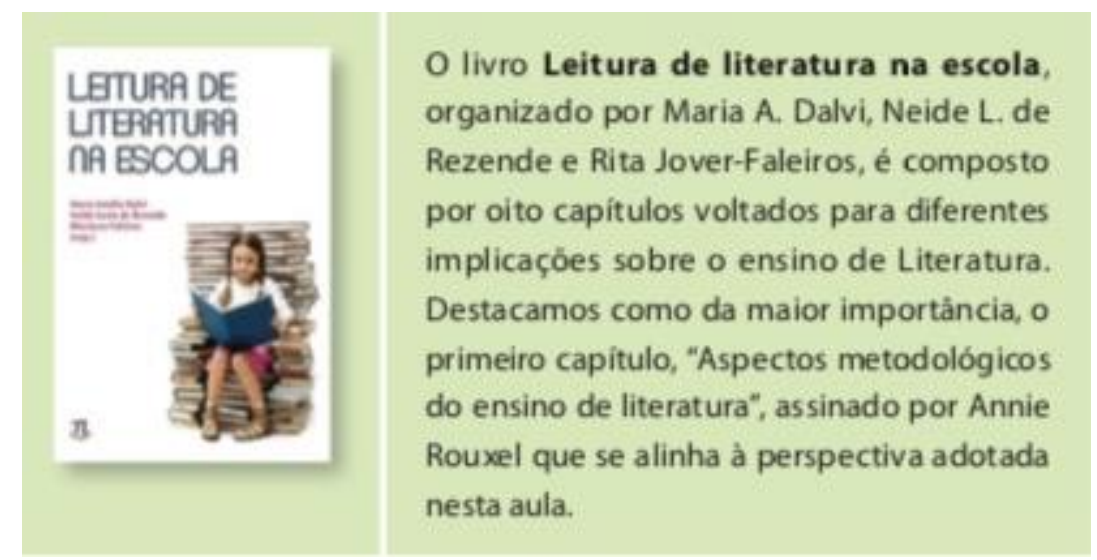

Fonte: IFPB, 2014, p. 22

Figura 2 - Recomendação de leitura da aula 1 do componente MEL

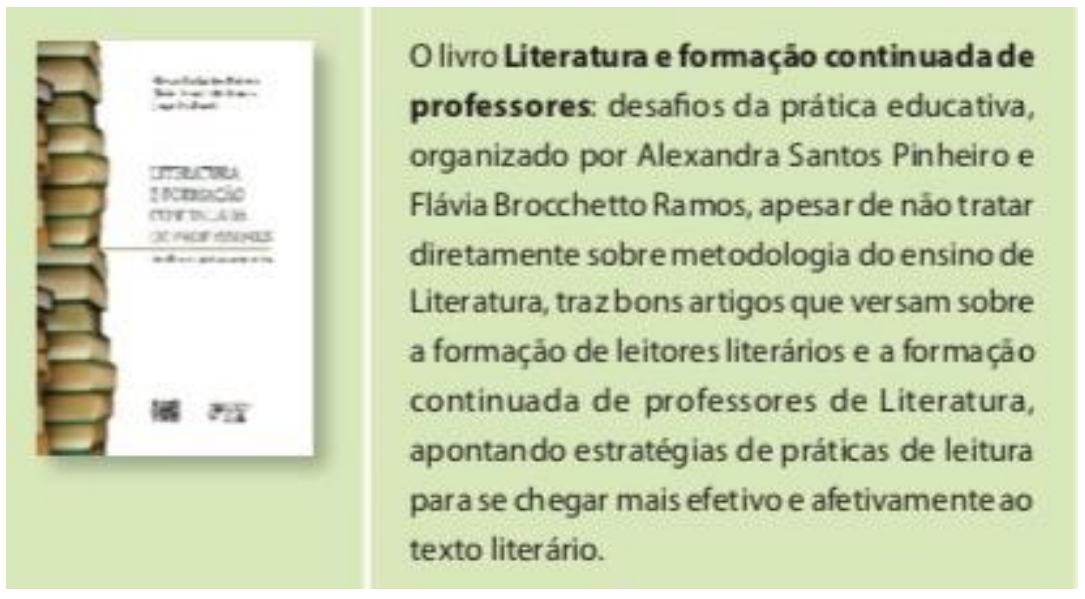

Fonte: IFPB, 2014, p. 23

Adiante, no tópico "Trocando em miúdos", a aula sumariza o que foi estudado e encerra o texto reiterando a flexibilidade que as metodologias comportam:

Veja que é um leque de possibilidades para se trabalhar o texto literário na sala de aula. Entretanto, é preciso lembrar que esses métodos não são uma "camisa de força", mas, antes de tudo, uma indicação de um percurso a ser seguido, que deve se adequar a diferentes realidades dos alunos/leitores/receptores. (IFPB, 2014, p. 23). 
E, no último item da aula denominada “Autoavaliando", apresenta as seguintes reflexões que devem ser exploradas pelos cursistas:

1) A partir dessas sugestões sou capaz de pensar em uma aula que priorize uma prática de ensino de literatura que se volte para a interação do texto com o leitor?

2) $\mathrm{O}$ que posso fazer para desconstruir nosso modo tradicional de ensinar literatura, pautado quase sempre pelos livros didáticos?

3) Diante de tantas sugestões, será que sou capaz de escolher uma que se adeque melhor à realidade de cada turma que eu possa lecionar?

A autorreflexão sugestionada pelos questionamentos conduz os licenciandos a pensarem no fazer docente, na relação teoria - prática, favorecendo a criação de pontes entre esses dois saberes e conferindo importância ao planejamento de metodologias para o ensino de literatura. Essas reflexões certamente colaboram para a prática pedagógica, visto que o gênero poema pode despertar nos graduandos, e por extensão aos seus futuros alunos, o “exercício da reflexão, a aquisição do saber, a boa disposição para com o próximo, o afinamento das emoções, a capacidade de penetrar nos problemas da vida, o senso da beleza, a percepção da complexidade e do mundo dos seres, o cultivo do humor", conforme defende Candido (1995, p. 249).

Discorrida a abordagem da poesia no Ensino Fundamental na aula 1 constante do material didático do IFPB, trataremos, agora, do conteúdo da aula 2 - "Poesia no ensino fundamental", cujos objetivos visados são:

- Proporcionar uma vivência criativa com uma das formas da poesia lírica;

- Estimular a interdisciplinaridade entre poesia e outras linguagens (IFPB, 2014, p. 27).

Tais objetivos corroboram a ideia defendida por Osakabe (2005, p. 49) ao advogar que "a poesia produz no leitor, como qualquer obra de arte, uma percepção nova sobre determinada experiência, ou constitui ela própria uma experiência renovada, como se guardasse sempre o frescor da sua criação."

No primeiro tópico da aula, "Começando a história", ao apresentar o tema a ser trabalhado, alguns princípios norteadores do ensino de poema na sala de aula são destacados:

1) ler e reler oralmente os poemas; 2) atentar para as diferentes realizações orais dos alunos, do (a) professor (a); 3) partir sempre da leitura dos poemas e não de informações sobre o autor ou o contexto, o estilo etc. Quando o poema oferecer algum tipo de dificuldade inicial, pode-se trazer informações que contribuam para uma leitura mais significativa. A ideia é sempre favorecer o enfrentamento do leitor em formação com o texto literário e não oferecer um saber a ser memorizado. Por outro lado, o professor necessita se preparar a fim de poder contribuir com este encontro do leitor com o texto. Isto significa ler anteriormente os poemas que serão 
trabalhados, estudar a riqueza da linguagem, aspectos temáticos que se destacam, aspectos de natureza visual, repetições, alusões etc. Não para ministrar uma aula expositiva sobre o "tema", mas para contribuir, por meio de perguntas, questões, questionamentos, sugestões com a formação do leitor. (IFPB, 2014, p. 28).

Tais princípios constituem informações necessárias para que o docente em formação compreenda que, além de adoção de metodologias construídas teoricamente, deverá concentrar-se no ler poético, atentando para os efeitos que pode suscitar no leitor-ouvinte. Desse modo, não se lê um poema da mesma forma que se lê um conto, posto que os recursos rítmicos, sonoros, os jogos de palavras, tão presentes nos poemas para crianças etc., devem ser explorados durante a leitura, a fim de provocar o encontro do leitor com o texto literário.

Em “Tecendo conhecimento", tópico destinado ao estudo de métodos e estratégias para se trabalhar o texto poético no Ensino Fundamental, a aula é iniciada com a apresentação de um poema curto de um poeta paraibano, Saulo Mendonça:

\section{Um gato}

$$
\begin{gathered}
\text { sobre a balança: } \\
\text { sono pesado. }
\end{gathered}
$$

Após a citação do poema, a aula segue com uma das leituras que o texto pode desencadear no leitor, destacando que a temática enfatiza uma cena comum cujos significados nem sempre são percebidos. A breve análise apresentada na aula tem o mister de chamar a atenção para os efeitos que o uso da linguagem pode provocar, fazendo-nos "perceber aspectos da natureza, das experiências humanas sob perspectivas diferenciadas.” (IFPB, 201-, p. 29). Seguindo essa breve introdução, a aula passa a tratar do haikai, expondo que, em estudo desse tipo de texto em sala de aula, recomenda-se a leitura de vários desses poemas, sem que o professor leve informações sobre a origem desse tipo de poema e sobre a sua composição formal, o que só deve ocorrer posteriormente, assim como dados sobre o autor.

A proposta da aula do componente curricular estudado é bastante interessante ao passo que retrata uma estrutura poética não muito conhecida, bem como apresenta um poeta local, informando o cursista acerca de obras produzidas e do posicionamento de um crítico literário sobre o livro do qual foi retirado o haikai citado.

No subtópico "A leitura de haikai”, a aula propõe uma metodologia para se trabalhar o haikai, a qual segue as seguintes etapas: no primeiro passo, se dá o momento de leitura e de releitura de "uma pequena antologia com diferentes formas líricas [...], ode, soneto, balada, 
canção, haikai, elegia etc.” (IFPB 2014, p. 30), perquirindo-se dos alunos os tipos poéticos conhecidos; no segundo passo, o professor, de acordo com a metodologia proposta, trabalha com o haikai, de origem japonesa, "um tipo de poema curto, que revela uma percepção aguda da natureza, nascido de uma observação meditativa [...]” (IFPB, 2014, p. 30); no terceiro passo, o professor passa a "estimular uma conversa sobre nossa relação com a natureza sendo de observação, descoberta de belezas escondidas em pequenos lugares, determinados momentos do dia etc." (IFPB, 2014, p. 31); no quarto passo, há o estímulo dos alunos para notarem as percepções captadas pelo poeta e para identificarem essas cenas do quotidiano percebidas.

O propósito da metodologia, como a aula deixa bem explícito, é o deleite dos poemas, é o contato com o texto lírico, observando os recursos empregados pelo poeta, sem um tratamento utilitarista da literatura. Tal objetivo metodológico é coerente com a etapa escolar, sobretudo, por não se preocupar nesse momento com análise estruturais do gênero. Dessa forma, o material não recorre a metodologias que se dedicam à escansão, à "observação do jogo das formas" (ROUXEL, 2013b, p. 155), em detrimento do sentido que o leitor atribui ao texto, conforme preceitua a teoria do leitor subjetivo defendida por Annie Rouxel (2013b). Nesse sentido, o material didático de Letras do IFPB compreende o ensino de literatura:

Essa convivência com os poemas, sem pressa, é fundamental para formarmos
leitores. Aqui, o que importa não é propriamente uma produtividade, no sentido de
ler o maior número de poemas possíveis, antes, é deixar calar/falar dentro de si uma
imagem, uma ideia, uma percepção. O professor necessita desta vivência para poder
ajudar a fomentá-la entre seus alunos. (IFPB, 2014, p. 31).

No subtópico seguinte, "Redescobrindo o próprio espaço", a aula propõe uma nova metodologia, partindo da leitura de haikais, com o objetivo de "estimular a captação de outras imagens e, a partir delas, a criação de pequenos poemas - que poderiam assumir a forma do haikai." (IFPB, 2014, p. 32). Assim, após a leitura dos poemas, o próximo passo proposto pela aula - inspirado no método criativo de Aguiar e Bordini (1993) -, é capturar imagens por meio de câmeras ou de desenhos, a fim de se estabelecer um diálogo entre o que foi recolhido. Em um novo momento, o material poderia ser separado por tema ou outro critério, para, então, criarem frases curtas ou versos como uma espécie de legenda das imagens. "Cumprida esta etapa, seria interessante expor para a escola o resultado - imagens textos - por meio de cartazes, de data show ou outros recursos como blogs e Facebook." (IFPB, 2014, p. 32). A aula ainda propõe um encontro com o poeta, o que "faz o maior 
sentido para os jovens leitores. E ainda favorece o questionamento do mito de que só se estudam na escola autores mortos.” (IFPB, 2014, p. 32).

No "Exercitando", momento em que o graduando pode avaliar a sua aprendizagem por meio de atividades sobre o tema, a aula apresenta outras duas autoras de haikai, Alice Ruiz e Maria Valéria Rezende, o que possibilita um contato maior com essa forma de poema.

No tópico "Aprofundando o conhecimento", a aula atenta o cursista para o fato de que, além de leitor literário, o professor deve ser também assíduo na leitura de crítica literária, a fim de dialogar com outras perspectivas com o fito de "construir um saber mais amplo sobre as obras literárias.” (IFPB, 2014, p. 34). Nesse sentido, a aula indica como leitura uma obra com ensaios sobre os haikais de Saulo Mendonça.

Figura 3 - Recomendação de leitura da aula 2 do componente MEL

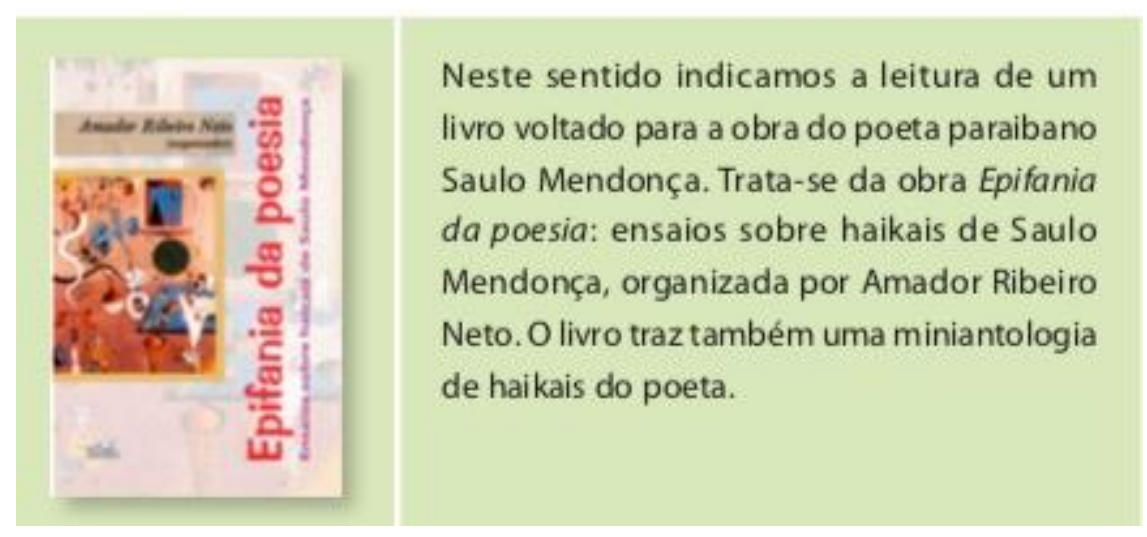

Fonte: IFPB, 2014, p. 34

Na seção "Trocando em miúdos”, é apresentada uma síntese da aula, ao passo que chama a atenção, no final, para a necessidade de o cursista vivenciar a leitura literária, "para ser um mediador sempre interessado na formação de leitores.” (IFPB, 2014, p. 35).

No último tópico, o "Autoavaliando", a aula convida o licenciando a refletir sobre sua vivência com a poema, a partir dos seguintes questionamentos:

1) Como tem sido minha convivência com a poesia? Sou um leitor assíduo, atento, envolvido?

2) Retomo várias vezes os poemas, leio e releio em voz alta?

3) Fico atento às ambiguidades, à sonoridade, aos recursos imagéticos que formam os poemas?

4) Parto ou partirei, em minhas aulas, sempre dos poemas e busco ou buscarei não um saber a ser ensinado, mas uma experiência a ser compartilhada? 
Como podemos perceber, as metodologias apresentadas na aula do componente Metodologia do Ensino de Literatura estão em consonância com os princípios das metodologias que visam à formação leitora do aluno, no sentido de fazê-lo experienciar e experimentar a leitura literária, sem maiores preocupações com o ensino analítico, historicista ou mesmo voltado para o ensino da língua portuguesa, formas de utilização do texto literário tão criticadas por estudiosos como Michèle Petit:

[n]a escola, por um longo período, estudou-se literatura como algo exterior, que não é vivido, constatado, sentido. Algumas abordagens são até mesmo voltadas para aprofundar a distância com o corpo, repudiar toda a emoção, vista como um desvario perigoso. E o corpo foi durante um bom tempo esquecido nas pesquisas sobre leitura, reduzida a uma atividade mental, enquanto o que se dá é uma atividade física, engajando de maneira indissolúvel corpo e mente. (2009, p. 63-64).

Como se vê, a autora levanta um ponto crucial, quando se fala em ler literatura ou ensinar literatura, a abordagem engessada do texto - perspectiva pragmática, despida de qualquer emoção, em que aluno tem que ler por dever e para responder uma série de perguntas que não trarão qualquer significado para sua história de leitura literária - a serviço, somente, da acentuação do temido afastamento livro-leitor.

Além da falta de emoção, Aguiar e Bordini apontam que as práticas, no ambiente escolar, têm enfatizado o emprego do livro didático no ensino da literatura, acarretando, consequentemente, o abandono da obra literária. Mas não é só isso,

[a]s fórmulas mais carentes de criatividade e mais tradicionalmente empregadas, como aulas expositivas e exercícios escritos e orais de interpretação, são praticadas pela maioria [dos professores], o que também promove a falta de incentivo e de motivação para a leitura dos alunos. (1993, p. 33).

O material didático do curso de Licenciatura em Letras modalidade EaD do IFPB, contrariamente, apresenta metodologias que: preconizam aulas participativas, opondo-se às aulas expositivas; visam à formação de leitores, mediante o contato direto com o texto integral e não fragmentos ou análises descontextualizadas; não trazem propostas utilitaristas, porém preceituam o despertar do gosto pela leitura, a criação de vínculos afetivos com o texto literário, valorizando a experiência do aluno-leitor, os sentimentos e as reações que lhe foram despertadas a partir da leitura. Nesse aspecto, compreendemos que essa forma de apresentar a poesia em sala de aula tende a desenvolver a imaginação, a criatividade, o lúdico e a sensibilidade do leitor. Tais procedimentos são defendidos por especialistas, a exemplo de Pinheiro (2000, p. 30), que afirma: 


\begin{abstract}
Mais que receitas, precisamos desenvolver e assumir algumas posturas quanto à leitura do poema e a leitura em geral. Atrevo-me a sugerir algumas destas posturas ao professor que deseja, em diferentes situações, levar a poesia a seus alunos: 1) não se fixar, de modo absoluto, no que deu ou não certo em experiências anteriores; 2) não buscar resultados imediatos e visíveis - nesse campo, há coisas sutis que nem sempre vemos; 3) ter constância no trabalho - é melhor ler diariamente um poema com seus alunos do que realizar um "festival de poesia", nos lembra Drummond; e por último, é imprescindível que o professor seja um leitor de poesia.
\end{abstract}

\title{
Considerações finais
}

A partir da análise do material didático empregado no curso de Licenciatura em Letras, modalidade $\mathrm{EaD}$, do IFPB, no tocante ao ensino do gênero poema no Ensino Fundamental II, percebemos que o conteúdo das aulas de Metodologia do Ensino da Literatura é atualizado, tanto teórico-metodologicamente, quanto no que diz respeito à preocupação de se atribuir ao texto literário a devida importância, ou seja, de "não usá-lo como pretexto" para o ensino da língua portuguesa ou de qualquer outro assunto que não o próprio texto literário. Nesse ponto, devemos ressaltar o uso ou utilização do texto ensinado por Rouxel ${ }^{7}$, tendo em vista que o professor nas leituras literárias, seja qual for o gênero, deverá dar voz ao leitor real, o nosso aluno, a fim de contribuir para sua aproximação com a literatura e o desenvolvimento do gosto literário. Nessa conjuntura, de fato, compreendemos as seguintes palavras de Cosson:

[...] aprendemos a ler literatura do mesmo modo como aprendemos tudo mais, isto é, ninguém nasce sabendo ler literatura. Esse aprendizado pode ser bem ou malsucedido, dependendo da maneira como foi efetivado, mas não deixará de trazer consequências para a formação do leitor. (COSSON, 2014b, p.29).

Partindo da ideia de que o poema é uma importante ferramenta pedagógica para despertar o senso poético, a sensibilidade e a imaginação do aluno, é possível adotar abordagens de leituras que favoreçam ao aluno conhecer, inferir e construir significados e quem sabe - elucidações sobre o mundo que o rodeia, transformando-o num leitor crítico, consciente de seu papel no seu universo e no meio social.

Portanto, caberá ao professor, como mediador, utilizar-se de metodologias que buscam a aproximação de seus alunos com o texto literário. Nesse ínterim, as aulas analisadas fornecem conhecimentos importantes que priorizam a leitura como deleite. Não obstante, a

${ }^{7}$ De acordo com Rouxel, “[a] interpretação visa, em verdade, a um consenso sobre um significado. Por sua vez, a utilização remete a uma experiência pessoal, que pode ser igualmente compartilhada.” (2013b, p. 162). 
aula que trata do gênero lírico se restrinja ao haikai, a especificidade desse tipo poético não oferece qualquer prejuízo para o professor em formação, podendo este levar quaisquer outros tipos de poemas a partir do que foi trabalhado nas aulas 1 e 2 do componente cujo material analisamos. Tendo em vista que a leitura deve ser um ato relevante na formação docente, e considerando que formar leitores tem sido um dos grandes anseios de professores e estudiosos dedicados à formação leitora de jovens, é certo que o caminho é continuar desenvolvendo práticas de leitura com base em metodologias que incentivam a sua autonomia, o seu pensamento crítico com estímulo a romper seus horizontes, construindo novos significados a partir do que foi lido.

\section{Referências}

AGUIAR, Vera Teixeira de; BORDINI, Maria da Glória. Literatura: a formação do leitor, alternativas metodológicas. Porto Alegre: Mercado Aberto, 1993.

BRASIL. MINISTÉRIO DA EDUCAÇÃO. Resolução $n^{o} 2$, de $1^{o}$ de julho de 2015 , do Conselho Nacional de Educação. Brasília: 2015.

CANDIDO, Antonio. Vários escritos. 3. ed. rev. e ampl. São Paulo: Duas Cidades, 1995.

COSSON, Rildo. Círculos de leitura e letramento literário. São Paulo: Editora Contexto, 2014a.

COSSON, Rildo. Letramento literário: teoria e prática. São Paulo: Editora Contexto, 2014b.

JORNAL FOLHA DE SÃO PAULO ONLINE. Veja o desempenho da sua escola no Enem 2018. Folha de São Paulo online, Educação. 18. jun.2019, Disponível em https://www1.folha.uol.com.br/educacao/2019/06/veja-o-desempenho-da-sua-escola-noenem-2018.shtml. Acesso: 30 ago. 2019.

INSTITUTO FEDERAL DE EDUCAÇÃO CIÊNCIA E TECNOLOGIA DA PARAÍBA. Projeto Pedagógico do Curso de Licenciatura em Letras na modalidade a distância. IFPB, 2012.

INSTITUTO FEDERAL DE EDUCAÇÃO CIÊNCIA E TECNOLOGIA DA PARAÍBA. Aula 1: Métodos do ensino da literatura. In: INSTITUTO FEDERAL DE EDUCAÇÃO CIÊNCIA E TECNOLOGIA DA PARAÍBA. Metodologia do ensino de literatura, 201-, p. $11-25$.

INSTITUTO FEDERAL DE EDUCAÇÃO CIÊNCIA E TECNOLOGIA DA PARAÍBA. Aula 2: Poesia no ensino fundamental. In: INSTITUTO FEDERAL DE EDUCAÇÃO CIÊNCIA E TECNOLOGIA DA PARAÍBA. Metodologia do ensino de literatura, 201-, p. 27-37. 
LAJOLO, Marisa. Do mundo da leitura para a leitura do mundo. 6 ed. $13^{\mathrm{a}}$ impressão. São Paulo: Editora Ática, 2008.

OSAKABE, Haquira. Poesia e Indiferença. In: PAIVA, Aparecida, et al. (Orgs.). Leituras literárias: discursos transitivos. Belo Horizonte: Autêntica, 2005, p.35-54.

PETIT, Michèle. A arte de ler ou como resistir à adversidade. Trad. de Arthur Bueno e Camila Boldrini. São Paulo: Editora 34, 2009.

PINHEIRO, Helder. Poemas para crianças e jovens. In: PINHEIRO, Helder. (org.). Poemas para crianças: reflexões, experiências, sugestões. São Paulo: Duas Cidades, 2000, p. 11-32.

ROUXEL, Annie. Práticas de leitura: quais rumos para favorecer a expressão do sujeito leitor? Cadernos de Pesquisa, v. 42, n. 145, p. 272-283, 2013 a.

ROUXEL, Annie. A tensão entre utilizar e interpretar na recepção de obras literárias em sala de aula: reflexão sobre uma inversão de valores ao longo da escolaridade. In: ROUXEL, Annie; LANGLADE, Gérard; REZENDE, Neide Luzia (org.). Leitura subjetiva e ensino de literatura. São Paulo: Alameda, 2013b, p. 152-164.

ROUXEL, Annie. Aspectos metodológicos do ensino da literatura. In: DALVI, Maria Almeida, REZENDE, Neide Luzia. JOVER-FALEIROS, Rita. (orgs.). Leitura de literatura na escola. São Paulo: Parábola, p. 17-33, $2013 c$.

ROUXEL, Annie. Mutações epistemológicas e o ensino da literatura: o advento do sujeito leitor. Revista Criação \& Crítica, n. 9, p. 13-24, 2012.

SALDAÑA, Paulo. TAKAHASHI, Fábio. Apesar de cortes, institutos federais lideram nota do Enem em 14 Estados. Folha de São Paulo online - Educação. 14. jan. 2018. Disponível em https://www1.folha.uol.com.br/educacao/2018/01/1950323-apesar-de-cortes-institutosfederais-lideram-nota-do-enem-em-14-estados.shtml. Acesso: 30 ago. 2019.

Recebido em 30 de agosto de 2019. Aceito em 16 de novembro de 2019. 